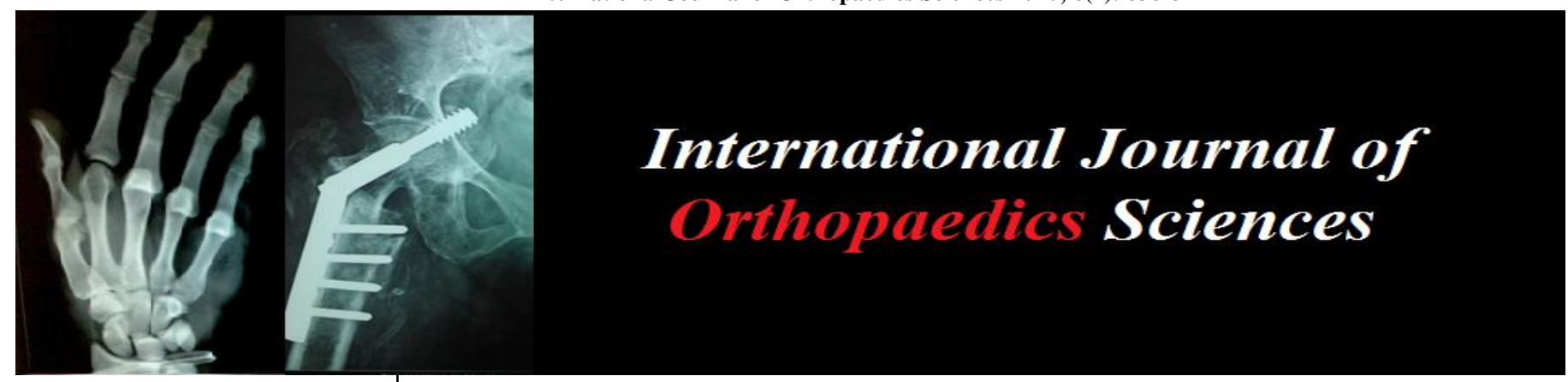

E-ISSN: 2395-1958

P-ISSN: 2706-6630

IJOS 2020; 6(4): 838-842

(C) 2020 IJOS

www.orthopaper.com

Received: 23-08-2020

Accepted: 26-09-2020

Dr. Sachin Onkar Phirke

Professor, Orthopaedics

Department, Dr. D.Y. Patil

Hospital, Kolhapur,

Maharashtra, India

Dr. Ravindra Patil

Associate Professor,

Orthopaedics Department, Dr.

D.Y. Patil Hospital, Kolhapur,

Maharashtra, India

Dr. Yash P Oza

2nd Year Resident, Orthopaedics

Department, Dr. D.Y. Patil

Hospital, Kolhapur,

Maharashtra, India

Dr. Ashwin Lokapur

2nd Year Resident, Orthopaedics

Department, Dr. D.Y. Patil

Hospital, Kolhapur,

Maharashtra, India

Dr. Shreyansh D Mehta

2nd Year Resident, Orthopaedics

Department, Dr. D.Y. Patil

Hospital, Kolhapur,

Maharashtra, India

Dr. Tushar Sinha

2nd Year Resident, Orthopaedics

Department, Dr. D.Y. Patil

Hospital, Kolhapur,

Maharashtra, India

\section{Assessment of the functional outcome of proximal humerus fracture following "PHILOS" plating}

\author{
Dr. Sachin Onkar Phirke, Dr. Ravindra Patil, Dr. Yash P Oza, Dr. \\ Ashwin Lokapur, Dr. Shreyansh D Mehta and Dr. Tushar Sinha
}

DOI: https://doi.org/10.22271/ortho.2020.v6.i41.2429

\section{Abstract}

Objective: The aim of our study was to evaluate the functional outcome using Constant-Murley scoring and grading system and complications of proximal humeral fractures in the elderly Indian population treated with proximal humerus internal locking system (PHILOS).

Method: A prospective study was carried out in a tertiary care center in Kolhapur. A total number of 46 patients with fracture of proximal humerus (NEERs 2 part, 3part \& 4part) were studied between January 2019 and Oct 2020. All were treated with PHILOS via deltopectoral approach. A mean follow up of 12 months was carried out, and evaluation was done with the help of Constant-Murley scoring and grading system.

Result: The mean radiological union time was 16 weeks. The outcome was measured using ConstantMurley scoring and grading system. Average follow up period was 12 months with good patient satisfaction. Total of 11 patients out of 46 reported complications like Malunion (4.50\%), Shoulder Joint Stiffness (17.80\%), Infection (8.90\%) and Implant Loosening (2.20\%). No case of peripheral neuropathies reported in any of the patients.

Conclusion: PHILOS plating via deltopectoral approach is a good treatment option showing good clinical outcome in the treatment of proximal humerus fracture (NEERs 2/3/4 part). It offers a more stable fixation and deltopectoral approach gives better exposure for the surgery.

Keywords: Proximal humerus, PHILOS, locking plate, deltopectoral approach

\section{Introduction}

Proximal humeral fractures are very common fracture of old age, contributing $4 \%-5 \%$ of all fractures overall and are nearly half $(45 \%)$ of all humeral fractures ${ }^{[1,2]}$. In people over age of 65 years, after fractures of the hip and distal radius, proximal femoral fracture is the third most common fracture ${ }^{[3]}$. In patient older than 50 years mostly present with low velocity injuries like simple fall, senile osteoporosis and menopausal changes in female are contributory factor for proximal humerus fracture following trivial trauma in old age patients. Though very common in old age these fractures show a bimodal distribution occurring either in children following high energy trauma ${ }^{[3]}$. Most of $(85 \%)$ these fractures are minimally displaced and give good results with immobilization followed by early motion. If it is displaced or unstable, it will require operative management ${ }^{[4]}$.

The Neer fracture classification system is very useful for clinical assessment of and research for fractures of proximal humerus. Neer has described 4 anatomical segments-greater tuberosity, lesser tuberosity, articular surface and shaft. The system is based on anatomic relationship of these segments. If 2 segments show displacement of $>1 \mathrm{~cm}$ or minimum angulation of 45 degrees it is considered separated. NEER's 2 part, 3 part and 4 part fractures require surgical intervention ${ }^{[5]}$.

Although various surgical techniques were described for the unstable Proximal Humerus Fracture, proximal humeral internal locking systems (PHILOS) are gaining popularity for treating these fractures. The PHILOS plate provides better biomechanical property by divergent and convergent fixed-angle screws. The divergent-convergent screw pattern provides better pull-out strength in osteoporotic bone and improves fixation stability.

This outcome depends on the age, medical condition, bone quality and also the expectations of
Corresponding Author: Dr. Sachin Onkar Phirke Professor, Orthopaedics Department, Dr. D.Y. Patil Hospital, Kolhapur, Maharashtra, India 
the patient. Surgical techniques used traditionally are open reduction and internal fixation with proximal humerus plate, intramedullary nail and percutaneous pinning or screw fixation, or the hemiarthroplasty as last resort. Problems associated with previous techniques were Implant loosening or failure of the implant and nonunion ${ }^{[6,7]}$. Despite numerous available treatment strategies, the management of complex proximal humeral fractures remains demanding and there is still no treatment that can be the golden standard in these fractures. Osteoporotic bone and comorbidities impairing postoperative care poses a challenge in older patients treated operatively.

AO/ASIF group developed the PHILOS (The Proximal Humeral Internal Locking Osteosynthesis) plate (Synthes, Stratec Medical Ltd, Mezzovico Switzerland). It is an internal fixation system which provides angled stabilization with multiple interlocking screws ${ }^{[8-16]}$. The aim of this study is to evaluate and analyze the clinical outcomes of the PHILOS in the treatment of Proximal Humerus Fracture in the elderly.

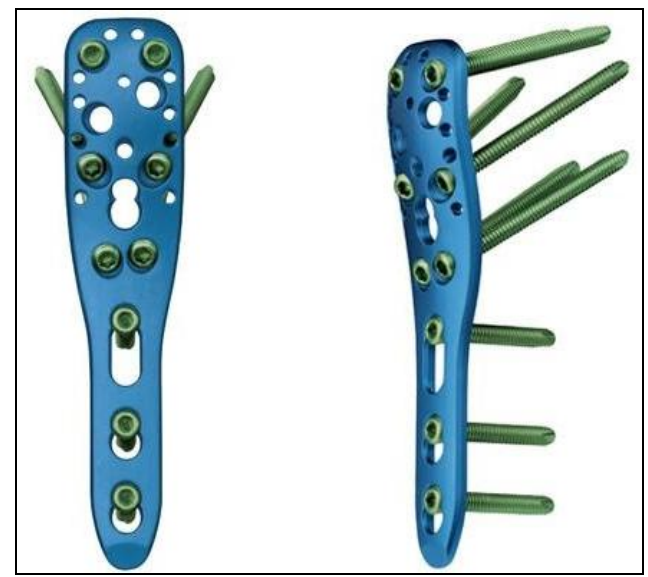

Fig 1: PHILOS plate system with screws ${ }^{[17]}$

\section{Aim}

The aim of our study was to evaluate the functionality using Constant-Murley scoring and grading system and complications of proximal humeral fractures in the elderly Indian population treated with proximal humerus internal locking system (PHILOS).

\section{Materials and methods}

This is a prospective study done from January 2019 to October 2020, in 46 patients of proximal humerus fractures with NEERs 2/3/4 part. All patients were treated with PHILOS plating via deltopectoral approach in a tertiary care center in Kolhapur. All patients included in our study were between 40 to 75 years of age (Mean age 54 years). Simple random method was used as the study sampling method.

\section{Inclusion criteria}

a. Patients undergoing PHILOS surgery for NEER's 2 part/3 part/4 part fracture with deltopectoral approach

b. Closed fractures

c. Patient of both sexes

d. Patient of age $>40$ years

\section{Exclusion criteria}

a. Patients having pre-existing deficit in shoulder function

b. Patient with prior surgery around the shoulder joint.

c. PHILOS done for proximal $1 / 3^{\text {rd }}$ shaft humerus fracture

Plain radiograph of the concerned shoulder with AP (antero- posterior) and axial views were taken along with $\mathrm{CT}$ of the concerned shoulder with 3D reconstruction done.

\section{Written informed consent was taken from all patients prior to surgery}

The Constant-Murley score and grading were used as evaluation criteria for the calculation of functional outcome of the patient.

\section{Surgical technique}

All 46 patients were operated at a tertiary care center in Kolhapur. All patients were operated under general anesthesia in supine position. Proximal humerus was exposed with a traditional deltopectoral approach. Very gentle dissection was done taking care of the soft tissue and maintaining good vascularity. Then anatomical fracture reduction is achieved, and the PHILOS plate is applied onto the proximal humerus. Getting the correct version of the humerus is the technically demanding part of the operation while applying the plate. The implant is temporarily fixed with a K-wire through hole in it to set height. If it is too high there is a risk of impingement, and it cannot be too low as there will be insufficient holes to put the screws into the head of humerus. Polyester sutures passed into the rotator cuff muscle around the fracture to aid to maintain reduction, these sutures are passed into the holes in the PHILOS plate \& tied. Locking screws of appropriate length were fixed in the plate.

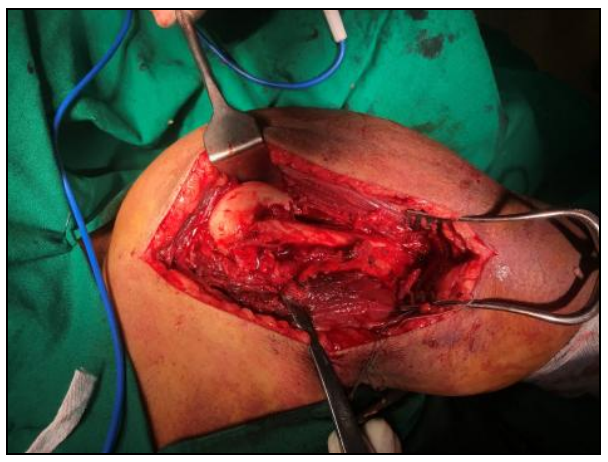

Fig 2: Surgical Exposure-Deltopectoral Approach

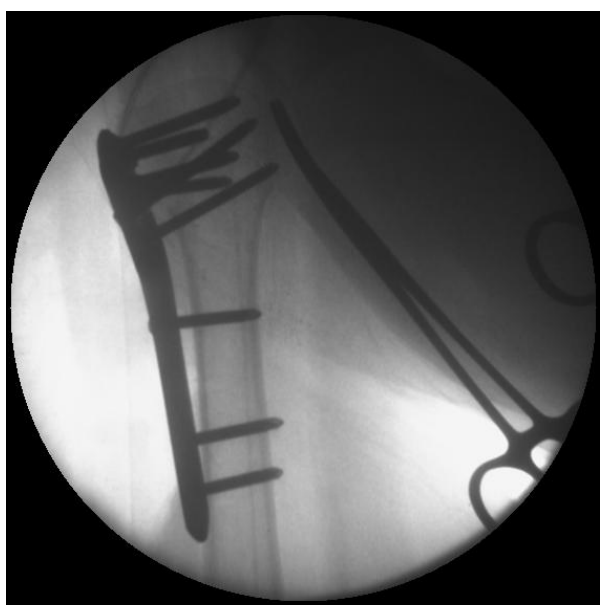

Fig 3: PHILOS plate Intraoperative Fluoroscopy

\section{Physiotherapy regime}

Physiotherapy is a very crucial part of post-operative care which consisted of pendulum exercises and intermittent use of arm sling for 3 weeks, followed by active assisted exercisesexternal rotation to neutral and flexion exercise. At 6 weeks they were allowed full range of movements. 


\section{Result}

A total of 46 patients were included in the study. One patient was lost to follow up. Of the remaining 45 patients, the mean age of the patient was 54 years. 21 patients $(45.6 \%)$ were males and 25 patients $(54.4 \%)$ were females. Right sided involvement (27 patients) was more frequent in the study than left side involvement (19 patients). Comorbidity like hypertension (11 patients), Diabetes mellitus (5 patients) and both hypertension and diabetes mellitus ( 5 patients) has been seen in present study.

Table 1: Age wise Patient distribution

\begin{tabular}{|c|c|c|c|}
\hline & Male & Female & Total \\
\hline Count & 21 & 25 & 46 \\
\hline Average Age & 54.6 & 53 & 53.8 \\
\hline Age Range & 45 to 73 & 40 to 65 & 40 to 65 \\
\hline
\end{tabular}

Table 2: Age groups of patients in our study

\begin{tabular}{|c|c|c|c|}
\hline & Male & Female & Total \\
\hline $40-50$ & 8 & 12 & 20 \\
\hline $50-60$ & 8 & 9 & 17 \\
\hline $60-70$ & 4 & 4 & 8 \\
\hline 73 & 1 & - & 1 \\
\hline \multicolumn{2}{|l}{ Patient was Included in 60-70 age group for convenience } \\
\hline
\end{tabular}

Table 3: Mechanism of Injury (Sex of Patient \& Mean Age)

\begin{tabular}{|c|c|c|c|c|c|c|}
\hline MOI & \multicolumn{2}{|c|}{ Trivial trauma } & \multicolumn{3}{c|}{ RTA } \\
\hline & Total & Male & Female & Total & Male & Female \\
\hline Count & 25 & 11 & 14 & 21 & 11 & 10 \\
\hline Ave Age & 57 & 60 & 55 & 47 & 46 & 48 \\
\hline
\end{tabular}

21 patients $(45.6 \%)$ sustained the fracture due to road traffic accidents and 25 patients $(54.4 \%)$ had a trivial trauma.

All the fractures were classified using the NEERs Classification system. 19 patients $(41.3 \%)$ were NEERs 2part, 17 patients $(36.9 \%)$ were NEERs 3-part, and whereas 10 patients $(21.8 \%)$ were NEERs 4-part fractures.

Table 4: NEER'S Classification

\begin{tabular}{|c|c|c|c|}
\hline NEERs & Male & Female & Total \\
\hline 2 part & 7 & 12 & 19 \\
\hline 3 part & 11 & 6 & 17 \\
\hline 4 part & 3 & 7 & 10 \\
\hline
\end{tabular}

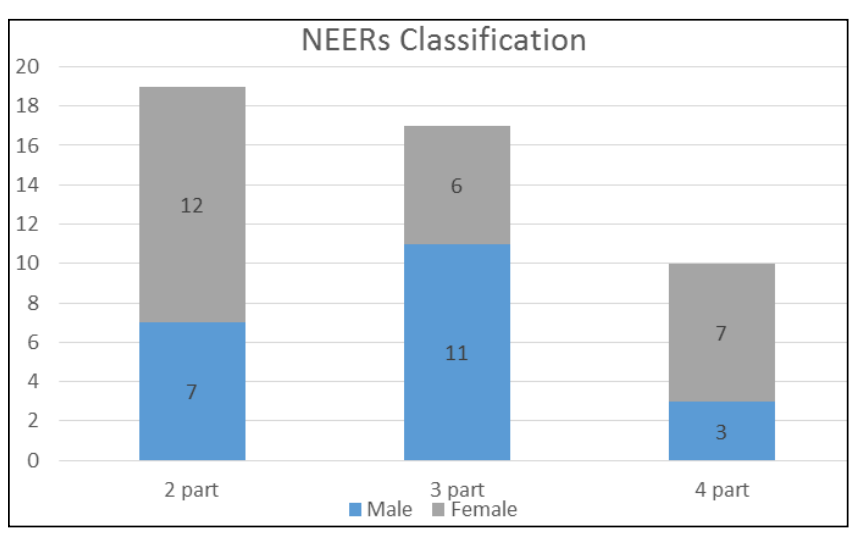

Chart 1: NEER's Classification

The mean time taken between onset of injury and surgical intervention was 4.1 days. The average duration of surgery was 86 minutes. There were no cases of neurovascular injury encountered in the present study. The average duration of the radiological union was 16 weeks in $27(60 \%)$ cases, 15 weeks in $12(26 \%)$ cases, 20 weeks in $6(14 \%)$ cases.

Regarding the complications, Shoulder Joint Stiffness was seen in 8 cases $(17.7 \%)$, infection in 4 cases $(8.8 \%)$, malunion in 2 cases $(4.4 \%)$ and Implant loosening in only 1 case $(2.2 \%)$. The infection was in the superficial plane and was treated with daily dressing and the appropriate antibiotics after isolating the organism by pus culture and sensitivity method. There was no recurrence of infection in that case. There were no cases of deep infection encountered in the present study. No cases of nonunion were observed. None of the patients in the present study required shoulder immobilizer after 3 weeks post-operatively. $3(6.6 \%)$ patients started physiotherapy after 4 weeks postoperatively due to poor compliance.

All the patients were followed-up at 6 weeks, 3 months, 6 months and 12 months post-operatively. The outcome was calculated using the Constant-Murley scoring and grading.

Table 5: Constant subjective assessments (average)

\begin{tabular}{|c|c|c|c|}
\hline $\begin{array}{c}\text { Age } \\
\text { group }\end{array}$ & $\begin{array}{c}\text { Pain score } \\
\text { out of 15 }\end{array}$ & $\begin{array}{c}\text { Work/Recreational } \\
\text { /Sleep Out of 10 }\end{array}$ & $\begin{array}{c}\text { Position Of shoulder \& } \\
\text { Average score-out of 10 }\end{array}$ \\
\hline $40-50$ & 13.25 & 7.75 & Neck to top of Head (7) \\
\hline $50-60$ & 10 & 6.5 & Up to Neck (5.5) \\
\hline $60-70$ & 8.5 & 5.5 & Up to Xiphoid (4.5) \\
\hline Overall & 11.25 & 6.75 & Up to Neck (6) \\
\hline
\end{tabular}

(Constant Subjective Assessment:

Pain score-No Pain-15, Mild Pain-10, Moderate Pain-2 and Severe Pain-0

Activity Limitation (Work/Recreational)-No limitation-4, Moderate limitation-2, Severe Limitation-0

Sleep Undisturbed-2, Sleep Disturbed-0

Position of shoulder-Above Head-10, Head-8, Neck-6, Xiphoid-4, Waist-2)
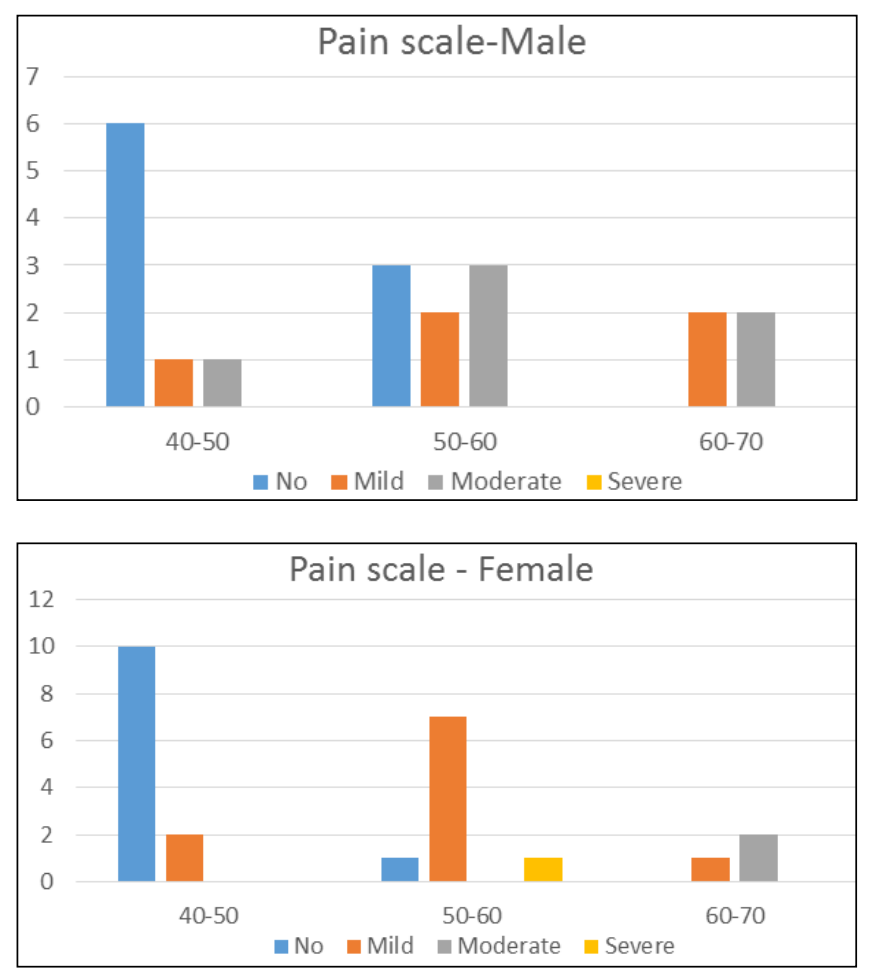

Chart 2: Constant Pain scale 
Table 6: Constant subjective assessments (average)-Gender wise

\begin{tabular}{|c|c|c|c|c|c|c|}
\hline Age Group & \multicolumn{2}{|c|}{ Pain Score } & \multicolumn{2}{c|}{ Work/Recreational/Sleep } & \multicolumn{2}{c|}{ Position of shoulder (average score)-out of 10 } \\
\hline & Male & Female & Male & Female & Male & Female \\
\hline $40-50$ & 12.75 & 13.5 & 8.25 & 7.85 & 7.75 & 6.5 \\
\hline $50-60$ & 10.5 & 9.5 & 6.5 & 6.38 & 5 & 3 \\
\hline $60-70$ & 8.5 & 8.5 & 6.25 & 4 & 5.5 & 6 \\
\hline Overall & 11 & 11.5 & 7 & 6.75 & 6 & 3 \\
\hline
\end{tabular}

Table 7: Constant objective assessments (average)-Range of Motion

\begin{tabular}{|c|c|c|c|c|c|}
\hline $\begin{array}{c}\text { Age } \\
\text { Group }\end{array}$ & $\begin{array}{c}\text { Flexion Abduction \% } \\
\text { of ROM Achieved }\end{array}$ & Internal Rotation & External Rotation & $\begin{array}{c}\text { Total Average } \\
\text { Score (40/40) }\end{array}$ \\
\hline $40-50$ & $70-80 \%$ & $75-80 \%$ & Upto T12 level & Hands behind head, elbows back & 31.6 \\
\hline $50-60$ & $50-60 \%$ & $60-70 \%$ & Upto Waist (L3) & Hands to the top of the head, elbows forward & 24.6 \\
\hline $60-70$ & $45-55 \%$ & $55-65 \%$ & Upto Waist (L3) & Hands to the top of the head, elbows forward & 24.4 \\
\hline Overall & $63 \%$ & $70 \%$ & Upto Waist & Hands to the top of the head, elbows forward & 27.7 \\
\hline
\end{tabular}

Table 8: Constant score-Strength Assessment (out of 25)

\begin{tabular}{|c|c|c|c|}
\hline & Male & Female & Combined \\
\hline $40-50$ & 13.5 & 11.5 & 12 \\
\hline $50-60$ & 11.5 & 9 & 10 \\
\hline $60-70$ & 8 & 9.25 & 8.5 \\
\hline Overall & 11 & 9.5 & 10.25 \\
\hline
\end{tabular}

Table 9: Constant Score Total (Out of 100)

\begin{tabular}{|c|c|c|c|}
\hline & Male & Female & Combined \\
\hline $40-50$ & 72 & 66 & 69 \\
\hline $50-60$ & 55 & 51 & 53.6 \\
\hline $60-70$ & 52 & 49 & 50.8 \\
\hline Overall & 61 & 59 & 60 \\
\hline
\end{tabular}

It showed excellent results in $14(31.2 \%)$, good in $20(44.5 \%)$, fair in $7(15.5 \%)$ and poor in $4(8.8 \%)$. The mean ConstantMurley score was $60 / 100$ in patients. Mean follow up duration was 12 months.

Table 10: Result according to NEER's fracture type

\begin{tabular}{|c|c|c|}
\hline $\begin{array}{c}\text { NEER's } \\
\text { Classification }\end{array}$ & $\begin{array}{c}\text { Average } \\
\text { Score }\end{array}$ & \\
\hline 2 Part & 72 & 9 Excellent, 9 Good (\& 1 Loss of follow up) \\
\hline 3 Part & 58 & 4 Excellent, 8 Good, 3 Fair, 2 Poor \\
\hline 4 Part & 40 & 1 Excellent, 3 Good, 4 Fair, 2 Poor \\
\hline
\end{tabular}

\section{Discussion}

Proximal humerus fracture fixation in elder patients is a challenging problem. Most of the undisplaced proximal humerus fracture is treated conservatively by a shoulder immobilizer. Previously displaced fracture of proximal humerus fracture was treated with different surgical methods like conventional plates, percutaneous pinning, suturing and screws, intramedullary nailing, has unsatisfactory functional outcome. Recently use of less invasive procedures for fracture fixation is in trend for early mobilization and decreases discomfort of patients.

In osteoporotic bone Fixation of proximal humeral fractures with plates and screws has been associated with complications such as pullout of screws, subacromial impingement. Excessive periosteum stripping can cause avascular necrosis of humeral head ${ }^{[18]}$. Kristiansen and Christensen have reported use of a T-buttress plate in proximal humerus fixation and they reported a high incidence of fixation failure [19]. Wijgman et al. have included 3-part and 4-part proximal humerus fractures with average age of 48 years in their study and reported good results at intermediate and long-term in $87 \%$ of patients treated with T-buttress plate ${ }^{[20]}$. Newer implants are introduced for proximal humerus fixation like
Plan tan humerus fixation plate, Polaris nail and the PHILOS plate. The plan tan humerus fixator plate on the humeral shaft 2 cancellous compression screws in the humeral head together with a plate is placed [21]. But this implant shows poor outcome in elder patients because of poor bone stock. Polaris nails have shown some favorable results in young and elder patients in 2 part proximal humerus fracture.

For minimal invasive procedure bone stoke should be good, patients should be willing for good participation in postoperative physiotherapy. Proximal humerus locking plates have good results in proximal humerus fractures has been proven in many studies. This study shows surgical management of proximal humerus fracture fixation by PHILOS via deltopectoral approach. In our present study fracture occurs in 21 male and 25 female, in which 27 fractures occur on the right side while 19 occurs on the left side. 25 patients had only a history of trivial trauma, with a mean age of 57 years in these groups. Gerber reported, in their study out of 34 fractures, 18 proximal humerus fractures were on the right side and 16 proximal humerus fractures were on the left side ${ }^{[22]}$. In fracture pattern 2 part fracture found to be most common in our study. Björkenheim et al. 8 By contrast, Koukakis et al., Rose et al., Siwach et al., and Fankhauser et al., had reported 3 part fractures had significant higher incident ${ }^{[23]}$. Mean age in our study is 54 years. Thyagarajan et al., in their study included 30 patients (Mean age-57.5 Years) of NEER's 2-part, 3-part and 4-part fractures and reported an average Constant score of $57.5^{[24]}$.

All patients in our study were treated with a PHILOS plate via deltopectoral approach. Total 8 patients out of 45 have been reported with shoulder joint stiffness. Total 5 patients out of this 8 had NEERs 4 part fracture and 3 patients had NEERs 3 part fracture. 2 patients were reported with Malunion. 4 patients were reported with infection. All patients reported with infection were treated with antibiotics after culture sensitivity reports and infection was superficial and not deep. No patient was reported with recurrent infection and no patient has been operated for early implant removal because of infection.

Regular follow up has been taken at 6 week, 3 month, 6 month and 12 month after operation. For assessment of functional outcome Constant-Murley scoring and grading system is used. Mean score of constant-Murley in NEERs 2 part fracture is 72 at end of 12 months. From all patients with NEERs 2 part fracture, 9 patients showed excellent results and 9 patients showed good results. Mean score of constantMurley in NEERs 3 parts fracture is 58 at end of 12 months. Out of which 4 patients showed excellent results, 8 patients showed good results, 3 patients showed fair results and 2 
patients showed poor results. In NEERs 4 part fracture constant-Murley mean score is 40 at end of 12 months, out of which 1 patient shows excellent result, 3 patients shows good results, 4 patients shows fair result and 2 patients shows poor results, in older age group patient with 4 part fracture owing to their poor bone quality and comminution it is difficult to achieve excellent outcome. All patients were present with good range of motion and comfortable with daily activity at 12 months of follow up.

Study shows good fracture fixation with no nonunion even in the osteoporotic bones. The PHILOS plate maintains fracture reduction and allows rapid union of the fracture with early mobilization of the shoulder joint. Deltopectoral approach in the management of displaced proximal humeral fractures gives a good exposure to fracture site.

\section{Reference}

1. Palvanen M, Kannus P, Niemi S, Parkkari J. Update in the epidemiology of proximal humeral fractures. Clin Orthop 2006;442:87-92.

2. Spence RJ. Fractures of the proximal humerus. Curr Opin Orthop 2003;14:269-80.

3. Baron JA, Barrett JA, Karagas MR. The epidemiology of peripheral fractures. Bone 1996;18(3):209S-13S.

4. Court-Brown CM, Garg A, McQueen MM. The epidemiology of proximal humeral fractures. Acta Orthop Scand 2001;72:365-71.

5. Carofino BC, Leopold SS. Classifications in brief: the Neer classification for proximal humerus fractures.

6. Nho SJ, Brophy RH, Barker JU, Cornell CN, MacGillivray JD. Management of proximal humerus fracture based on current literature. J Bone Joint Surg Am 2007;89(3):44-58.

7. Michael W, Andre F, Robert F. Locked plating: biomechanics and biology and locked plating: clinical indications. Techniques in Orthopaedics. 2007;22(4):20918.

8. Fankhauser F, Boldin C, Schippinger G, Haunschmid C, Syzszkowitz R. A new locking plate for unstable fractures of the proximal humerus. Clin Orthop Relat Res 2005;430:176-81.

9. Koukakis A, Apostolou CD, Taneja T, Korres DS, Amini A. Fixation of proximal humerus fractures using the PHILOS plate: early experience. Clin Orthop Relat Res 2006;442:115-20.

10. Kettler M, Biberthaler P, Braunstein V, Zeiler C, Kroetz M, Mutschler W. [Treatment of proximal humeral fractures with the PHILOS angular stable plate. Presentation of 225 cases of dislocated fractures]. Unfallchirurg German 2006;109:1032-40.

11. Südkamp N, Bayer J, Hepp P, Voiqt C, Oestern H, Kabb $\mathrm{M}$ et al. Open reduction and internal fixation of proximal humeral fractures with use of the locking proximal humerus plate. Results of a prospective, multicenter, observational study. J Bone Joint Surg Am 2009;91(6):1320-8.

12. Aggarwal S, Bali K, Dhillon MS, Kumar V, Mootha AK. Displaced proximal humeral fractures: an Indian experience with locking plates. J Orthop Surg Res 2010;5:60.

13. Bigorre N, Talha A, Cronier P, Hubert L, Toulemonde JL, Massin P. A prospective study of a new locking plate for proximal humeral fracture. Injury 2009;40(2):192-6.

14. Yang H, Li Z, Zhou F, Wang D, Zhong B. A prospective clinical study of proximal humerus fractures treated with a locking proximal humerus plate. J Orthop Trauma 2011;25:11-7.

15. Helwig P, Bahrs C, Epple B, Oehm J, Eingartner C, Weise K. Does fixed-angle plate osteosynthesis solve the problems of a fractured proximal humerus? A prospective series of 87 patients. Acta Orthop 2009;80:92-6.

16. Shahid R, Mushtaq A, Northover J, Maqsood M. Outcome of proximal humerus fractures treated by PHILOS plate internal fixation. Experience of a district general hospital. Acta Orthop Belg 2008;74:602-8.

17. Wijgman AJ, Roolker W, Patt TW, Raaymakers EL, Marti RK. Open reduction and internal fixation of three and four part fractures of the proximal part of the humerus. J Bone Joint Surg Am 2002;84:1919-25.

18. Kristiansen B, Christensen SW. Plate fixation of proximal humeral fractures. Acta Orthop Scand 1986;57:320-3.

19. Lind T, Krøner K, Jensen J. The epidemiology of fractures the proximal humerus. Arch Orthop trauma Surg 1989;108:285-7.

20. Sadowski C, Riand N, Stern R, Hoffmeyer P. Fixation of fractures of the proximal humerus with plant tan humerus fixator plate: Early experience with a new implant. J Shoulder Elbow Surg 2003;12:148-51.

21. Gerber C, Worner CM, Vienne P. Internal fixation of complex fractures of the proximal humerus. J Bone Joint Surg (Br) 2004;86(60):P 848-55.

22. Björkenheim JM, Pajarinen J, Savolainen V. Internal fixation of proximal humeral fractures with locking compression plate: A retrospective evaluation of 72 patients followed for a minimum of 1 year. Acta Orthop Scand 2004;75:741-5.

23. Thyagarajan DS, Haridas SJ, Jones D, Dent C, Evans R, Williams R. Functional outcome following proximal humeral interlocking system plating for displaced proximal humeral fractures. Int. J Shoulder Surg. 2009;3(3):57-62. Doi: 10.4103/0973-6042.59971. PMID: 20671866; PMCID: PMC2907001. 